\title{
Evaluation of Oral Anticoagulant Use in Atrial Fibrillation Patients
}

\author{
Gestina Aliska $^{1}$, Erlina Rustam ${ }^{1}$, Elly Usman ${ }^{1}$, Ivan Mahendra Raditya ${ }^{2}$ \\ aliska@med.unand.ac.id ${ }^{1}$ \\ ${ }^{1}$ Department of Pharmacology and Therapeutic, Faculty of Medicine, Andalas University. \\ ${ }^{2}$ Residency Programme of Cardiology and Vascular Medicine, Faculty of Medicine, Andalas University.
}

\begin{abstract}
Oral anticoagulant (OAC) is used for thromboembolic prevention in atrial fibrillation (AF) patients. This study aim to observe the use of OAC in AF patients in a tertiary Hospital. We enrolled all patients with complete data of medical record. The data of the use of OAC in AF patients is taken from patients that was hospitalized in Cardiology ward during January 2015-August 2016. Patients were given OAC during hospitalization. Sixty three patients with atrial fibrillation were analysed in this study. Incidence of valvular disease was higher than non-valvular atrial fibrillation (65\% vs $35 \%$ patients). Most of the patients was women (67.4\%). Warfarin as oral anticoagulant for thromboembolic prevention was still more popular than dabigatran $(61.8 \%$ vs $34.2 \%)$. Almost of patients had low HAS-BLED score. The intrahospital bleeding occured in $6 \%$ of all patients given warfarin. Warfarin is still used as a mainstay therapy in AF patients for thromboembolic prevention. Bleeding rate due to warfarin use for hospitalized patients was rare.
\end{abstract}

Keywords: anticoagulants, bleeding, warfarin

\section{Introduction}

Atrial fibrillation (AF) is the most common cardiac rhythm disorder worldwide [1]. Prevalence AF at Harapan Kita Hospital, Indonesia in 2009 was 9.8\% [2]. Fifteen percent of AF patients will be had stroke[2-4]. In patients with $\mathrm{AF}$ at higher risk for thromboembolism, the use of oral anticoagulant such as warfarin (a vitamin K antagonist) or the newer anticoagulants could reduce morbidity and mortality [1]. In the other side, oral anticoagulant use carries a risk of bleeding, especially vitamin $\mathrm{K}$ antagonist [1]. Warfarin is the most common OAC that prescribed for AF patients $[2,4]$. New oral anticoagulant (NOAC) especially dabigatran is more frequently use for non-valvular AF but it is not coveraged by National Health Insurance for atrial fibrillation. Due to controversial use of NOAC in thromboembolism prevention, we need to evaluate the benefit and risk of oral anticoagulant in atrial fibrillation.

\section{Methods}

This study was a retrospective study from medical record of AF patients. All patients admitted to cardiology ward/intensive cardiovascular care unit (ICCU) with atrial fibrillation as primer or secondary diagnosis. Admission date of patients should be on January 2015 until August 2016. Inclusion criteria were patients above 18 years old), receiving OACs in hospital either warfarin or dabigatran. Exclusion criteria were uncompleted medical record. Sixty-seven patients were included in the study. $\mathrm{CHA}_{2} \mathrm{DS}_{2}$ Vasc and HAS-BLED score of all patients were calculated at pre-admission. 
The use of anticoagulant for non-valvular AF should consider stroke and bleeding risk [5]. Recent guidelines for non-valvular AF (NVAF) recommend the $\mathrm{CHA}_{2} \mathrm{DS}_{2}-\mathrm{VASc}$ score (congestive heart failure, hypertension, age [ $>75$ years], diabetes, stroke/transient ischemic attack, vascular disease, age [65-74 years], sex category [female]) for stroke risk stratification [6,7]. HAS-BLED score (hypertension, abnormal renal or liver function, stroke history, bleeding history, labile international normalized ratio, age $>65$ years, drugs, or alcohol) was recommended for bleeding risk stratification [6].

Patients with $\mathrm{CHA}_{2} \mathrm{DS}_{2}$ Vasc score $\geq 2$ had higher stroke risk and recommend anticoagulant. If $\mathrm{CHA}_{2} \mathrm{DS}_{2}$ Vasc score $=1$ may use antithrombotic therapy with oral anticoagulant or antiplatelet. If $\mathrm{CHA}_{2} \mathrm{DS}_{2}$ Vasc score $=0$, antithrombotic therapy was not recommended. HAS-BLED score $\geq 3$ should be monitored regularly because high risk of bleeding [6].

This study described the use of oral anticoagulant for stroke prevention in patients with AF, including warfarin and dabigatran. Among patients treated with anticoagulant therapy, we also examined whether these patients were treated with an antiplatelet agent. Treatment with an antiplatelet agent was defined as prescription of aspirin and clopidogrel.

\section{Statistic analysis}

Baseline characteristic data were analysed as with SPSS version 17.0. Normally distributed continuous variables are expressed as means and standard deviations, whereas categorical variables are expressed as proportions.

\section{Ethical consideration}

This study was approved for ethical clearance from Ethical Committee of Faculty of Medicine, Andalas University.

\section{Results}

A total of 62 patients were included in the study. Baseline characteristics among patients are shown in Table 1. Female patients outnumbered males (44 vs. 23). Fifty-six percent patients were 40-64 years old. Body Mass Index (BMI) mean was $22.3 \pm 3 \mathrm{~kg} / \mathrm{m} 2$. More than half AF patients was non-valvular. Heart failure and hypertension were the common AF risk factors in our patients. Sixty-one percent of patients (41 of 67) received warfarin. 
Table 1. Baseline characteristics of atrial fibrillation patients

\begin{tabular}{|c|c|c|}
\hline Characteristics & Total $(n=67)$ & Percentage $(\%)$ \\
\hline \multicolumn{3}{|l|}{ Sex } \\
\hline Male & $23 / 67$ & 34.3 \\
\hline Female & $44 / 67$ & 65.7 \\
\hline Age (years) & $53.5 \pm 13.4$ & \\
\hline$<40$ & $13 / 67$ & 19.4 \\
\hline $40-64$ & $38 / 67$ & 56.7 \\
\hline$\geq 65$ & $16 / 67$ & 23.9 \\
\hline \multicolumn{3}{|l|}{ Valvular disease } \\
\hline Yes & $22 / 67$ & 32.8 \\
\hline No & $45 / 67$ & 67.2 \\
\hline \multicolumn{3}{|l|}{ Comorbidities } \\
\hline Chronic Heart Failure & $34 / 67$ & 50.7 \\
\hline Hypertension & $30 / 67$ & 44.8 \\
\hline Diabetes Mellitus & $3 / 67$ & 4.5 \\
\hline Dyslipidemia & $5 / 67$ & 7.5 \\
\hline Smoker & $12 / 67$ & 17.9 \\
\hline Body Mass Index* & $22.3 \pm 3$ & \\
\hline Underweight & $5 / 67$ & 7.5 \\
\hline Normal & $38 / 67$ & 56.7 \\
\hline Overweight & $17 / 67$ & 25.4 \\
\hline Obese I & $5 / 67$ & 7.5 \\
\hline Obese II & $2 / 67$ & 3.0 \\
\hline \multicolumn{3}{|l|}{ Anticoagulant } \\
\hline Warfarin & 41 & 61.2 \\
\hline Dabigatran & 26 & 38.8 \\
\hline
\end{tabular}

HAS-BLED score of patients were varied. Half of patients with warfarin therapy had HASBLED score $=0$ or no bleeding risk. Bleeding risk of patient was low-moderate. Figure 1 shows $3 / 4$ patients with high bleeding risk (HAS-BLED $\geq 3$ ) still received warfarin. Bleeding occur only in one patient. 


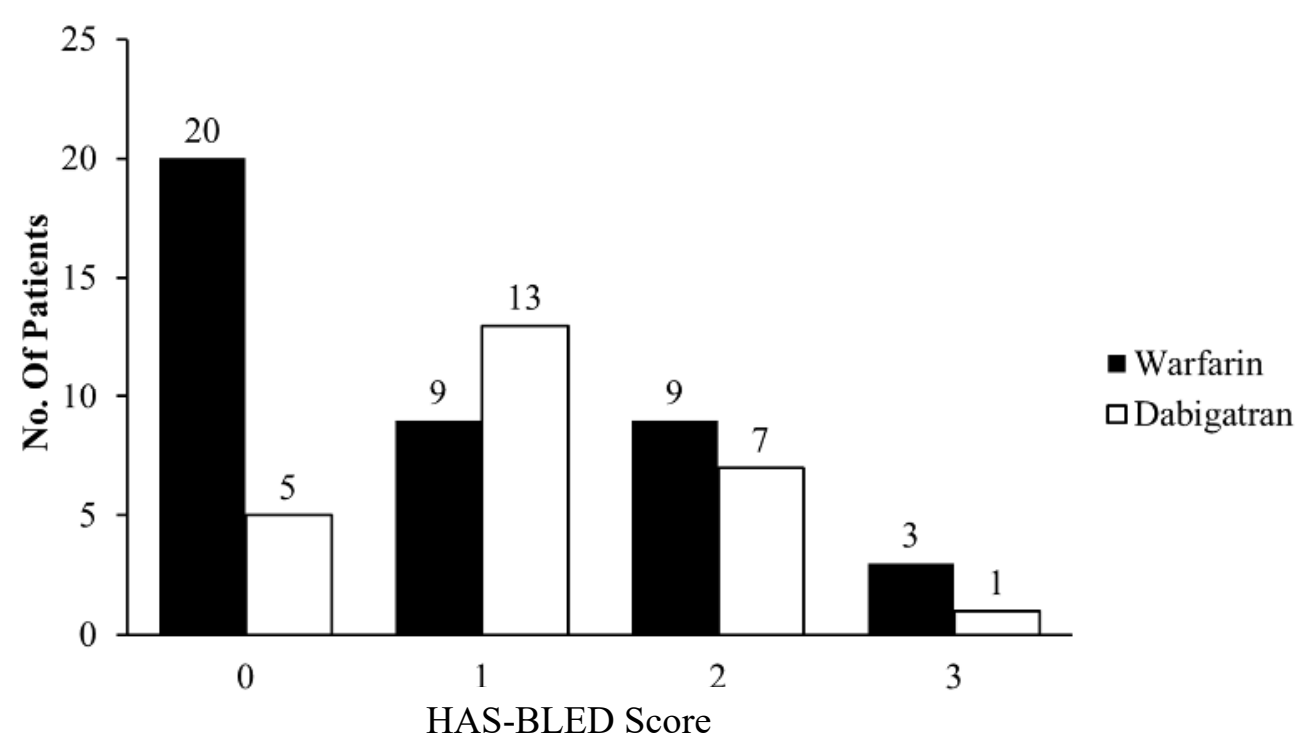

Figure 1. HAS-BLED score between warfarin and dabigatran group

Intrahospital bleeding occured only 4 of 67 patients. All of these patients received warfarin. Hypertension and older age increased bleeding risk in warfarin and dabigatran group (Table 2). Among 4 patients with intrahospital bleeding, 2 patients used concomitant low dose aspirin (Table 3). Bleeding still occur although the international normalised ratio (INR) was in target range for prevention thromboembolism.

Table 2. Bleeding risk between warfarin and dabigatran group

\begin{tabular}{lcc}
\hline & $\begin{array}{c}\text { Warfarin group } \\
(\mathbf{n = 4 1 )}\end{array}$ & $\begin{array}{c}\text { Dabigatran group } \\
(\mathbf{n = 2 3})\end{array}$ \\
\hline Intrahospital bleeding event & 4 & 0 \\
HAS-BLED score & & 15 \\
Hypertension & 11 & 2 \\
Abnormal liver/renal & 5 & 0 \\
function & 3 & 2 \\
Stroke history & 3 & 0 \\
Bleeding history & 0 & 10 \\
Labile INR & 6 & 2 \\
Age $>$ 65 & 6 & \\
Drug / alcohol & &
\end{tabular}


Table 3. Clinical condition of patients with intrahospital bleeding

\begin{tabular}{clcccccc}
\hline Patient & Sex & $\begin{array}{c}\text { Ag } \\
\text { e }\end{array}$ & INR & $\begin{array}{c}\text { HAS- } \\
\text { BLED } \\
\text { score }\end{array}$ & $\begin{array}{c}\text { Abnormal } \\
\text { renal / liver } \\
\text { function }\end{array}$ & $\begin{array}{c}\text { Warfari } \\
\text { n dose }\end{array}$ & Concomitant drug \\
\hline 1 & Femal & 52 & 2.5 & 0 & No & $4 \mathrm{mg}$ & No \\
2 & $\mathrm{e}$ & 82 & 0.97 & 3 & Yes & $5 \mathrm{mg}$ & Aspirin low dose \\
3 & Male & 46 & 2.52 & 1 & No & $5 \mathrm{mg}$ & Aspirin low dose \\
4 & Male & 36 & 1.49 & 2 & No & $2.5 \mathrm{mg}$ & No \\
& Femal & & & & & & \\
& $\mathrm{e}$ & & & & & & \\
\hline
\end{tabular}

From subgroup analysis of non-valvular AF, $40 \%$ patients had high risk of stroke $\left(\mathrm{CHA}_{2} \mathrm{DS}_{2}\right.$ Vasc score $\geq 2$ ) (Figure 2). About $5 / 45$ patients with low stroke risk and do not need anticoagulant.

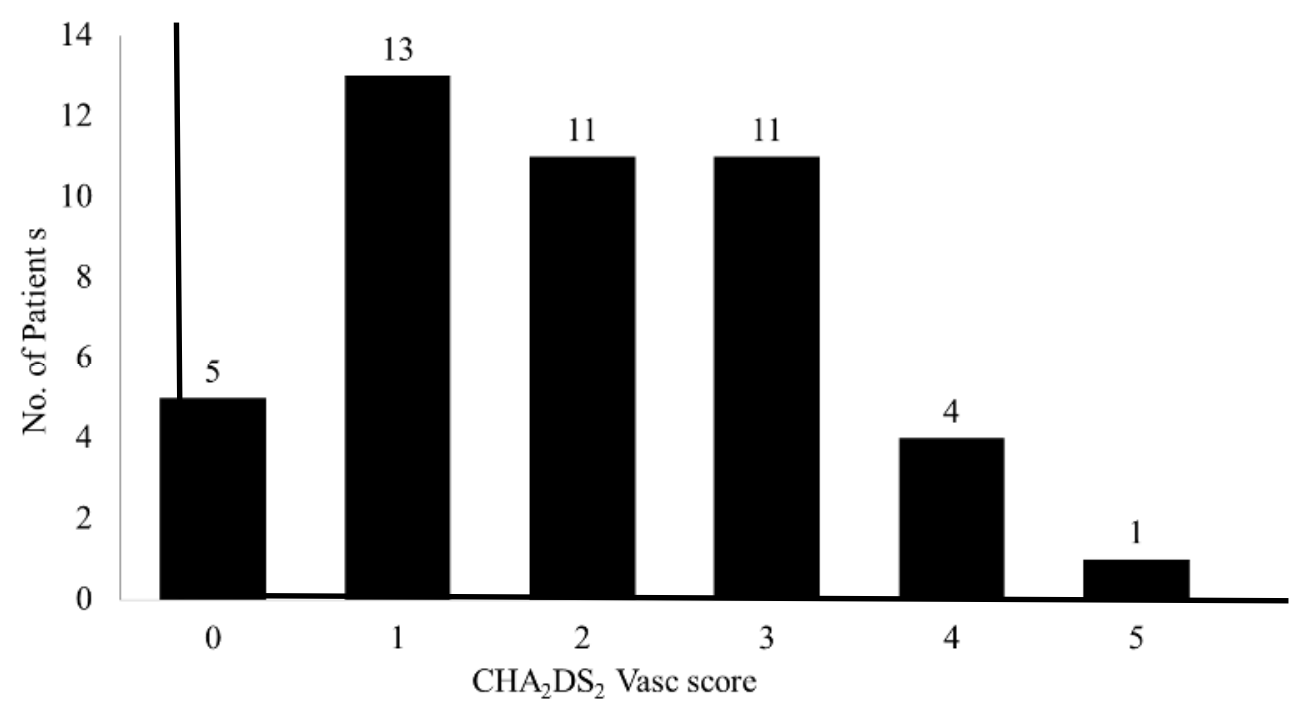

Figure 2. $\mathrm{CHA}_{2} \mathrm{DS}_{2}$ Vasc score distribution among non-valvular $\mathrm{AF}(\mathrm{n}=45)$

\section{Discussion}

This study found that female AF patient was higher than male. Its differ from Worldwide Epidemiology of Atrial Fibrillation and developing nations epidemiology which male outnumbered female[8,9]. The proportion of valvular and non-valvular AF showed that non-valvular AF was more common than valvular. Martinez et al also found the increasing incidence of non-valvular AF in UK in a decade.

The common risk factors for AF were advancing age, male sex, diabetes mellitus, hypertension, valvular disease, myocardial infarction, heart failure, obesity, elevated inflammatory marker concentrations, and PR-interval prolongation, as recently reviewed elsewhere [10]. From Farmingham Study, independent risk factors for AF were men gender, 
diabetes, hypertension, congestive heart failure, and valve disease [11]. Hypertension, valvular disease, and heart failure are the main risk factors for AF in our patients.

Al-Turaiki et al. revealed that most of the patients were at moderate $(63.3 \%)$ to high $(27.7 \%)$ risk of bleeding [12]. In this study, bleeding risk of patients was low-moderate. Risk of intrahospital bleeding in warfarin group was higher than dabigatran. Bleeding risk may increase by concomitant use of antiplatelet drugs, advancing age, and abnormal renal/liver function, eventhough the INR at first admission was below 3.0. Sarawate et al. report first INR on admission (INR >3.0) was associated with intrahospital bleeding (ORadjusted [95\%CI], 1.72 [1.02-2.90]) [13].

The $\mathrm{CHA}_{2} \mathrm{DS}_{2}-\mathrm{VASc}$ score was calculated for non-valvular AF patients. The $\mathrm{CHA}_{2} \mathrm{DS}_{2}-\mathrm{VASc}$ score includes categories of $0=$ low risk, $1=$ intermediate risk, and $\geq 2$ as high risk. About $40 \%$ non-valvular AF patients were high risk for stroke. Al-Turaiki et al found that $92 \%$ patients were high risk for stroke [12]. In this study, $40 \%$ patient high risk for stroke.

Many risk factors associated with the risk of bleeding in warfarin therapy such as older age [14]. One of patient (52 y.o) in warfarin therapy, with HAS-BLED score 0, still get bleeding. The annual rate of extracranial bleeding of warfarin therapy for patients under 60 years old is 0.28 [15].

\section{Conclusions}

Non-valvular atrial fibrillation is higher than valvular. Intrahospital bleeding occur in warfarin group, even the risk of bleeding in this patients is low. There are multifactorial risk factor for bleeding in patient who received warfarin, such as age, renal dysfunction, the use of aspirin low dose, warfarin dose and INR level. The use of warfarin as oral anticoagulant for non-valvular patient still recommended, but the therapeutic level plasma of warfarin should be monitored.

\section{References}

Hsu JC, Chan PS, Tang F, Maddox TM, Marcus GM. Oral Anticoagulant Prescription in Patients With Atrial Fibrillation and a Low Risk of Thromboembolism: Insights From the NCDR PINNACLE Registry. JAMA Intern Med. 2015 Jun;175(6):1062-5.

Indonesian Heart Association (2014). Guideline of Atrial Fibrillation. Indonesian Heart Association. Centra Communications. $1^{\text {st }}$ ed.p.11-35.

Zoni-Berisso M, Lercari, Carazza T, Domenicucci S (2014). Epidemiology of atrial fibrillation: European perspective. Clin Epidemiol.;6:213-20.

De Caterina R, Husted S, Wallentin L, Agnelli G, Bachmann F, Baigent C. Anticoagulants in heart disease: current status and perspectives. Eur Heart J. 2007 Apr;28(7):880-913.

Guo Y, Lip GY, Apostolakis S. Bleeding risk assessment in patients with atrial fibrillation who are taking oral anticoagulants. Hosp Pract (1995). 2013 Feb;41(1):71-8. 
Lane DA, Lip GY. Use of the CHA(2)DS(2)-VASc and HAS-BLED scores to aid decision making for thromboprophylaxis in non-valvular atrial fibrillation. Circulation. 2012 Aug 14;126(7):860-5.

Doğan V, Başaran Ö, Beton O, Tekinalp M, Aykan AÇ, Kalaycıŏglu E, et al. Gender-related differences in presentation and treatment of patients with non-valvular atrial fibrillation: results from RAMSES study. Turk Kardiyol Dern Ars. 2017 Jan;45(1):1625.

Chugh SS, Havmoeller R, Narayanan K, Singh D, Rienstra M, Benjamin EJ, et al. Worldwide epidemiology of atrial fibrillation: a Global Burden of Disease 2010 Study. Circulation. 2014 Feb 25;129(8):837-47.

Chugh SS, Roth GA, Gillum RF, Mensah GA. Global burden of atrial fibrillation in developed and developing nations. Glob Heart. 2014 Mar;9(1):113-9.

Rienstra M, McManus DD, Benjamin EJ. Novel risk factors for atrial fibrillation: useful for risk prediction and clinical decision making? Circulation. 2012 May 22;125(20):e9416.

Benjamin EJ, Levy D, Vaziri SM, D'Agostino RB, Belanger AJ, Wolf PA. Independent risk factors for atrial fibrillation in a population-based cohort. The Framingham Heart Study. JAMA. 1994 Mar 16;271(11):840-4.

Al-Turaiki AM, Al-Ammari MA, Al-Harbi SA, Khalidi NS, Alkatheri AM, Aldebasi TM, et al. Assessment and comparison of CHADS2, CHA2DS2-VASc, and HAS-BLED scores in patients with atrial fibrillation in Saudi Arabia. Ann Thorac Med. 2016 AprJun;11(2):146-50.

Sarawate C, Sikirica MV, Willey VJ, Bullano MF, Hauch O.Monitoring anticoagulation in atrial fibrillation. J Thromb Thrombolysis. 2006 Apr;21(2):191-8.

Fang MC, Go AS, Chang Y, et al. A new risk scheme to predict warfarin-associated hemorrhage: The ATRIA (Anticoagulation and Risk Factors in Atrial Fibrillation) Study. J Am Coll Cardiol. 2011;58(4):395-401.

Fang MC, Go AS, Hylek EM, et al. Age and the risk of warfarin-associated hemorrhage: the anticoagulation and risk factors in atrial fibrillation study. J Am Geriatr Soc. 2006;54 (8):1231-6. 